\title{
Hydraulic analysis of El Mahmoudia canal
}

\author{
H. M. Moghazy ${ }^{1}$, O. K. Saleh ${ }^{2}$ \& N. F. Abd El Azim ${ }^{3}$ \\ ${ }^{1}$ Irrigation Engineering and Drainage, Faculty of Engineering, \\ Alexandria University, Egypt \\ ${ }^{2}$ Department of Water and Water Structures Engineering, \\ Faculty of Engineering, Zagazig University, Egypt \\ ${ }^{3}$ Faculty of Engineering, Alexandria University, Egypt
}

\begin{abstract}
Egypt is facing increasing challenges in the water sector driven by the increased demand for water and increased pressures on the water resources of the River Nile. Due to the water challenges in Egypt, a number of integrated water management projects are starting to take place in order to improve the irrigation and drainage management and to increase the efficiency of irrigated agricultural water use and services. One of the projects adopted by the Ministry of Water Resources and Irrigation to face this problem is the Integrated Irrigation Improvement and Management Project in old lands to increase the efficiency of water use and achieve the optimum benefit. The main objective of the present paper is to study the hydraulic analysis of El Mahmoudia canal which is an important canal in the West Delta. The canal feeds Alexandria and El Beheira governorates with drinking and industrial demands in addition to irrigating about 120,000 Hectares. The results of a hydraulic model study are presented in this paper in order to identify the most effective physical interventions. An ISIS one dimensional hydraulic model was used to integrate the canal supplies and demands to assess the sensitivity of the water balance and canal performance to trends in demands. The canal is used to meet demands from Alexandria and hence the growth in municipal demands has been an important constraint on the management of water levels in the canal. The study has been developed to explore the sensitivity of the canal to key assumptions and parameters and therefore provides a valuable tool for establishing a strategy for on-going canal monitoring and a framework for managing the dynamics in water resources.

Keywords: El Mahmoudia canal, Egypt, integrated water management, water resources, canal efficiencies, hydraulic modelling.
\end{abstract}




\section{Introduction}

Egypt is facing increasing water needs, demanded by rapidly growing population, increased urbanization, higher standards of living and by an agricultural policy which emphasizes expanding production in order to feed the growing population. Abou Rayan and Djebedjian [1] stated that Egypt is passing now through the rapid population growth stage towards the stationary population growth stage. This stage is characterized by the slow decrease of the annual crude birth rate, against rapid decline of the crude death rate. Attia [2] also stated that the rapid population and urban growth leads to additional demand on Egypt's water resources.

MWRI [3] pointed out that there are significant challenges to water resources development and use in Egypt. Nile River being a single source of water is the main challenge, in addition to the developments upstream, and continued population and economic growths which will exert further pressure on the existing water resources. Allam and Allam [4] stated that the most significant issues and considerations facing the Government of Egypt as pertaining to water resources management are: population growth, agricultural expansion, fragmentation of agricultural land holdings, water pollution, lack of public awareness, lack of information, deficiency of legislation, climatic changes, in addition to potential conflicts with the Nile basin countries. Wagdy [5] added that the challenges facing the water sector in Egypt are enormous and require the mobilization of all resources and the management of these resources in an integrated manner. Accordingly, MWRI in Egypt has to launch national water resources management plans to safeguard Egypt's future water resources, both with respect to quantity and quality, and to use these resources in the best way. Furthermore, the MWRI has to endorse policies to achieve both integration and decentralization of water management to the lowest possible level.

\section{Irrigation water management}

Egypt is characterized by an arid climate with very limited rainfall. In spite of this, the combination of fertile soil, mild climate, and industrious farmers make Egyptian agriculture one of the most productive in the world, despite the fact that only about 3 to 3.7 percent of Egypt's land is arable, stated York et al. [6]. They added that the nation's agriculture is almost totally dependent upon irrigation. Consequently, agricultural development is closely linked to the water resources of the Nile River. The major water user in the Egyptian economy is the agriculture sector which accounts for approximately 85 percent of the total water diversions in Egypt. According to Hanna and Osman [7], Egypt can be split into two major regions with different agricultural and irrigation characteristics. The first is the Old Lands referring to lands along the Nile Valley and in the Delta which are irrigated from the Nile. The second is the New Lands referring to the newly reclaimed land located outside the Nile Valley and in the desert areas, which are viewed as an opportunity for increasing the cultivated land. Abu Zeid 
[8] stated that farmers in the New Lands are required by law to use sprinkler or drip irrigation system.

\subsection{Features of the old irrigation system in Egypt}

Egypt has the oldest irrigation system in the world which relies mainly on the Nile River. Hvidt [9] stated that the Egyptian irrigation system is tremendous in size and complexity. He added that the system distributes approximately 59 billion cubic meter of water annually, not only to cultivated land, but also for municipal and industrial use, to generate hydroelectricity, and for navigation of freighters and tourist boats.

Bader [10] stated that operation and maintenance of the irrigation system is the Government's responsibility. Ownership of the water system and enforcement of the law and legislation are also the Government responsibilities. The irrigation system in the old lands of the Nile Valley is a combination of gravity and water lifting systems. According to Abd El Azim [11], in the traditional irrigation system in the Old Lands, water is delivered to farmers under prescheduled upstream command and rotational basis.

Gersfelt [12] pointed out the limitations of upstream control including the difficulty of matching between supply and demand, which leads to a great possibility of having water shortages or water surpluses. He added that upstream control, gives the upstream farmers priority over tail end farmers. This means that the tail end farmers will not be allowed to irrigate unless the upstream ones have fully obtained their requirements. Moreover, Kotb and Boissevain [13] identified the rotational irrigation system drawbacks stating that the system is ill suited for cultivation of short-rooted crops like vegetables, which require more frequent irrigation, and it is very difficult to secure an even distribution of water along the canals, which in turn results in unequal water deliveries and so-called tail-end problems. Inadequate deliveries of water have led many farmers to manipulate the system in various ways to deliver larger amounts of water. In some locations, the rotation schedule is also observed somewhat loosely, making it difficult to predict when irrigation water will be available.

\section{Description of El Mahmoudia main canal}

El Mahmoudia main canal is an earthen canal of $77.100 \mathrm{~km}$ long starts from $\mathrm{km}$ 194.200 on the West side of Rosetta branch, and runs in a North-West direction where it ends in Alexandria harbor. The canal serves a net irrigated area of 120,000 Hectares in both Alexandria and El Beheira governorates. It provides water to 67 branch canals. The canal also supplies municipal and industrial water to Alexandria city, five other cities, and about 90 villages. The canal receives water from four sources: El Atf pumping station at $\mathrm{km} \mathrm{0.000,} \mathrm{Edko} \mathrm{pumping}$ station at $\mathrm{km} \mathrm{8.740,} \mathrm{the} \mathrm{tail} \mathrm{escape} \mathrm{of} \mathrm{El} \mathrm{Khndaq} \mathrm{El} \mathrm{Sharqi} \mathrm{canal} \mathrm{at} \mathrm{km} \mathrm{15.355,}$ and small re-use pumping stations feeding tail ends on some branch canals operated in summer when extra supplies are needed. 


\section{Development of EI Mahmoudia hydraulic model}

A hydraulic model of El Mahmoudia canal was developed using the ISIS software which is developed by Halcrow Group Limited. ISIS is a full hydrodynamic simulator for modelling flows and levels in open channels and estuaries with the ability to model a wide range of hydraulic structures. For hydraulic model set up basic information and data about El Mahmoudia command area were collected accompanied by layout and location maps. Other information including cross-sections at different locations, longitudinal sections, as well as structures, municipal and industrial off-takes along the canal were also collected. Moreover, location of all branch canals with their lengths, served areas, cropping patterns, and the water duty of the area were included. El Mahmoudia main canal has been identified by ISIS units and introduced to the model. Six-hundred and eighty-four units were identified along the canal. Figure 1 illustrates El Mahmoudia model network.

All branch canals, direct irrigation, municipal and industrial off-takes were included in the model as abstraction points. Branch canals and direct irrigation off-takes were entered into the model such that the flow into each is represented by a time variant flow to allow the model to explore strategies for controlling branch canal flows during periods of peak water use. Whereas, municipal and industrial demands were modeled as fixed flows, since, in the majority of cases only the peak flows were known. Branch canals served areas, published by Water Watch [14], were used to build up the hydraulic model together with their break down of crop types by branch canal for the 2008 summer season. A monthly water demand profile, based on analysis carried out by the Water

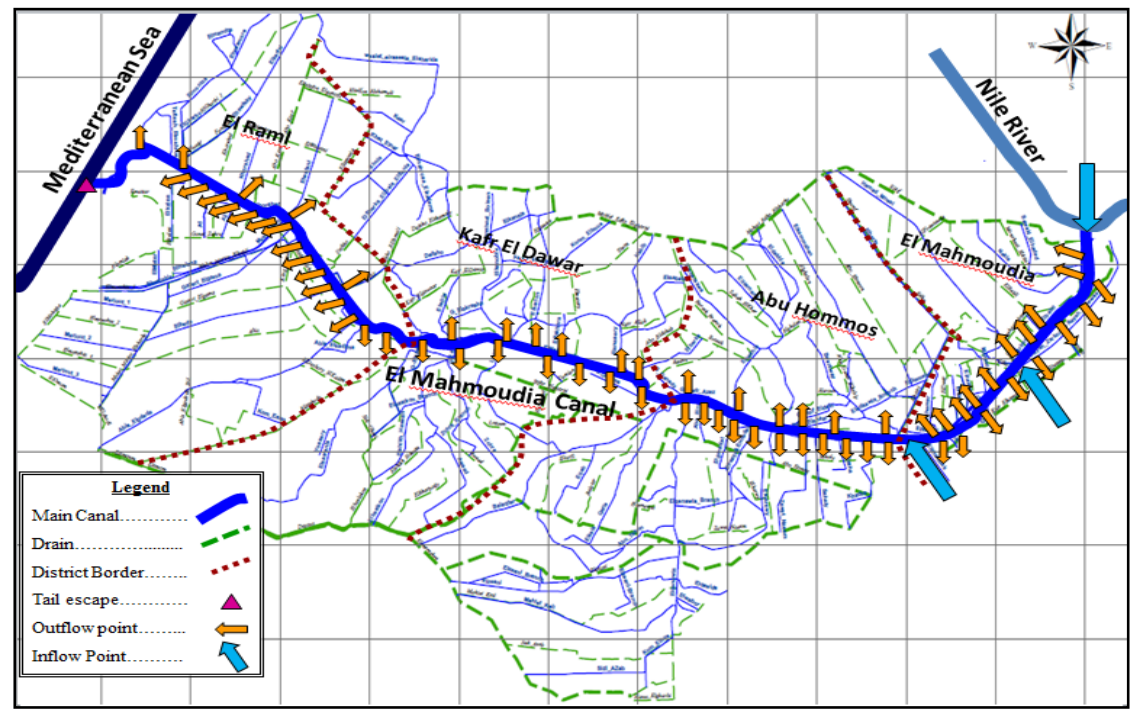

Figure 1: $\quad$ El Mahmoudia Model network. 
Management and Research Institute (WMRI), was applied to each branch canal in the model in addition to the Irrigation Improvement Sector (IIS) assumptions for application and conveyance efficiencies.

One sluice control unit was included to illustrate Kafr El Dawar lock and regulator at $\mathrm{km} 42.890$ followed by a Bernoulli loss unit to illustrate the energy loss downstream of the structure. The model for El Mahmoudia canal has been developed for the period April-September 2008, i.e., in the summer season when the flows in the main canal are greatest and the demands are most extreme.

\section{El Mahmoudia hydraulic model validation}

After the simulation run has been performed, the model was validated for the summer period of 2008. The maximum summer water levels used for the model calibration were abstracted from daily recorded water levels obtained from the Irrigation Sector (IS) at 37 locations between km 0.000 and Kafr El Dawar Lock for the year 2008, in addition to data at 19 locations downstream Kafr El Dawar Lock till $\mathrm{km}$ 65.570. These recorded water levels were used to establish optimum values of bed roughness and parameters to define head loss at bridges and the Kafr El Dawar flow regulator. The simulated and observed peak water levels for 2008 are presented in Figure 2.

In addition, the model was also validated using measured flows obtained from the WMRI for three locations; at the tail of El Khandaq El Sharqy canal, upstream El Khandaq El Sharqy confluence at km 15.145 on El Mahmoudia canal, and downstream Kafr El Dawar lock at km 43.100.

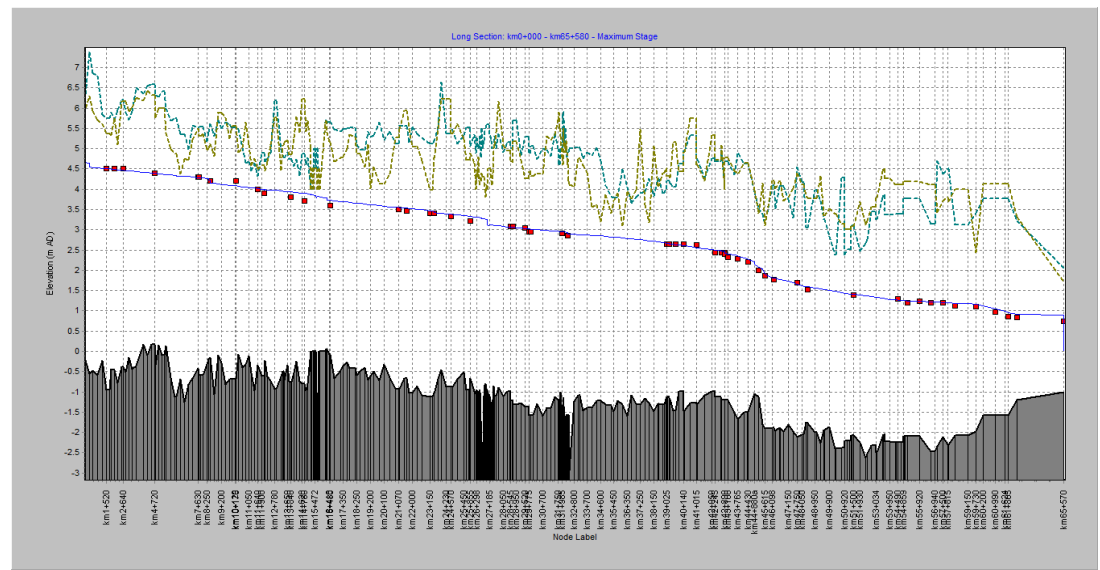

Figure 2: $\quad$ Calibration water levels for summer 2008.

\section{Review of baseline model scenario outputs}

The baseline model for El Mahmoudia canal has been developed and shown to be able to replicate the recorded water level and flow data along the canal for the 
peak discharges recorded in the summer season of 2008. The baseline scenario represents the current or existing situation of El Mahmoudia canal. Figure 3 presents the obtained water surface profiles for the simulation run. Where, the maximum simulated waterline in addition to a $0.50 \mathrm{~m}$ freeboard projected from the maximum simulated water levels is presented along with the minimum simulated waterline. The outlets levels of the branch canals off-taking from El Mahmoudia canal are also shown.

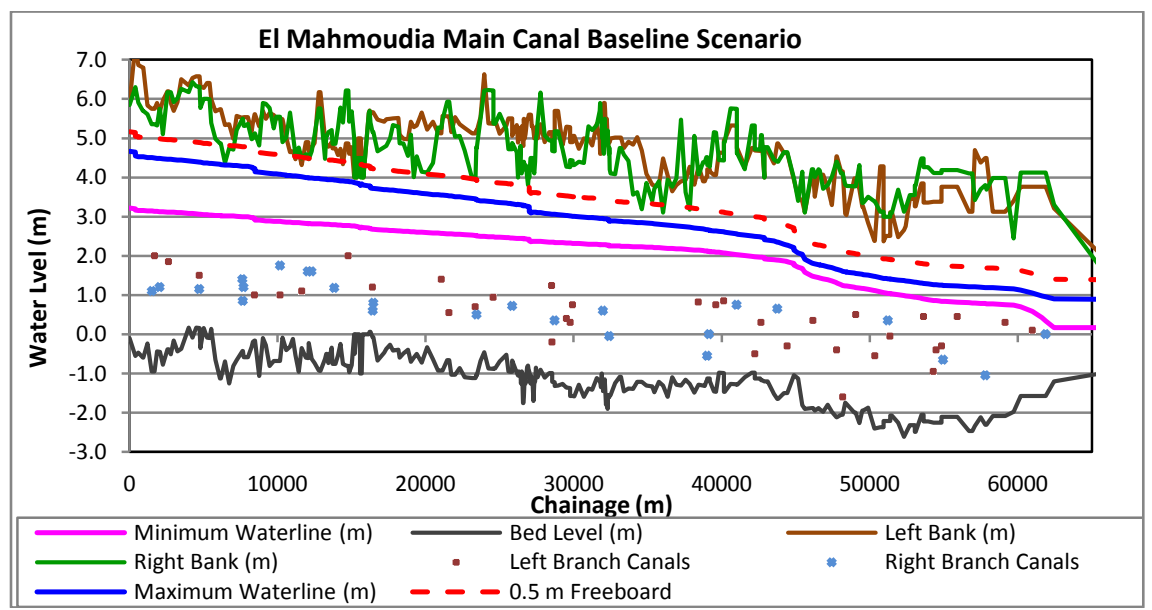

Figure 3: $\quad$ El Mahmoudia canal baseline scenario waterlines.

\section{Hydraulic simulation model}

In order to examine El Mahmoudia canal capacity to meet the expected future increase in municipal demands due to the rapid population growth and check its ability to deliver the required municipal, industrial and agricultural demands up to the year 2050, four scenarios have been studied using the ISIS simulation model. Scenarios have been chosen every 10 years to reflect the potential increase in municipal requirements and assess their impact on the hydraulic conditions of the existing system of El Mahmoudia canal. Where the scenarios cause the existing system to fail, potential interventions were postulated and their impact reviewed. These scenarios have been run through the ISIS model to assess the water levels in the main canal. In all scenarios the model assumed that El Atf pumping station is capable of pumping sufficient water into the main canal. Other inflows comprise the Edko re-use pumping station inflow and El Khandaq El Sharqy canal. Moreover, a stage-discharge relationship at El Khandaq El Sharqy confluence was developed in order to obtain the relationship between water levels in El Mahmoudia canal at $\mathrm{km} 15.355$ and the inflow from the tail of El Khandaq El Sharqy canal. It was concluded that; as the water level in El Mahmoudia canal, at $\mathrm{km} 15.355$, increases the flow capacity of El Khandaq El Sharqy canal decreases. 
Water balances have been prepared for the studied scenarios. These water balances basically assumed the branch canals served areas as published by the WaterWatch with monthly water demands based on the MWRI demand profiles. Whereas, the MWRI Decree 29, for the year 2010, sanctioned rice cultivation areas for Egypt was applied to the branch canal command areas starting from Scenario (2). As for the industrial demands, maximum daily amounts used by main industries fed from El Mahmoudia canal, provided by the Irrigation Sector, were used and kept constant throughout all the four studied scenarios. On the other hand, the municipal requirements, which are considered the key element in the presented scenarios, were increased throughout the different scenarios based on the population estimates presented in the Central Agency for Public Mobilization and Statistics (CAPMAS) [15].

\section{Scenario (1) up to the year 2020}

In this scenario, the canal capacity to pass the projected discharges up to the year 2020 was examined. Water balance for this scenario was developed by increasing the inflow from El Atf pumping station each month in order to satisfy the 2020 projected municipal requirements. Whereas, inflow from El Khandaq El Sharqy was reduced through June to August in order to balance the junction at El Khandaq El Sharqy confluence, and the difference was taken from El Atf pumping station. The inflow from Edko re-use pump station was kept unchanged. The maximum and minimum waterlines up to the year 2020 are presented in Figure 4.

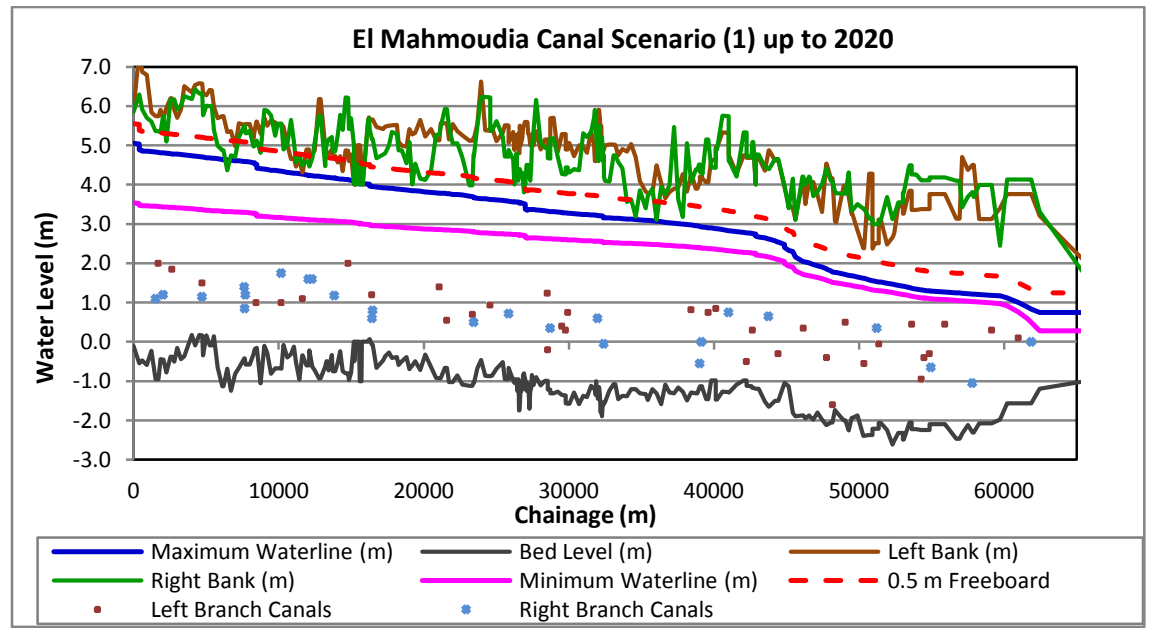

Figure 4: $\quad$ El Mahmoudia canal waterlines up to the year 2020.

Scenario (1) resulted in an increase of approximately $40 \mathrm{~cm}$ in the maximum water levels at El Atf pumping station (km 0.000). Whereas, water levels

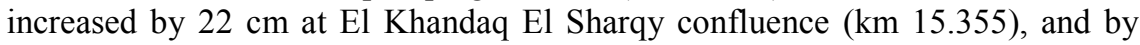




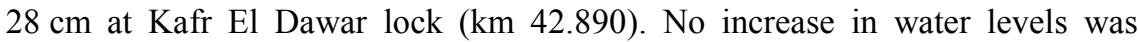
encountered downstream of El Seyouf water treatment plant (km 62.460), which is the largest drinking water plant on El Mahmoudia canal, until the end of the canal. Areas of low freeboard (less than $50 \mathrm{~cm}$ ) were observed at some locations along El Mahmoudia canal. It is recommended to raise the embankments at these.

\section{Scenario (2) up to the year 2030}

In order to pass the projected discharges up to the year 2030, due to the increase in the municipal requirements, Decree 29:2010 for cultivated rice areas was introduced to all branch canals command areas. In addition to introducing drainage water re-use from seven existing re-use pump stations in June, July and August. These re-use pump stations each can provide a maximum of $1.0 \mathrm{~m}^{3} / \mathrm{sec}$. They supply water to three branch canals off-taking from El Mahmoudia canal (El Qinaweya km 28.544, Balaqtar km 29.775, and El Saaraniah km 44.433). Moreover, inflow from El Atf pumping station was increased to reach the maximum capacity of the pump stations in July (which is 14 million $\mathrm{m}^{3} /$ day). The additional required inflow was taken from Edko re-use pump station, taking into consideration that the inflow from Edko does not exceed the maximum allowable rate of 1.0 million $\mathrm{m}^{3} /$ day. Again, inflow from El Khandaq El Sharqy canal was reduced through June to August, in order to balance the junction at El Khandaq El Sharqy confluence, as in Scenario (1). Figure 5 presents the maximum and minimum waterlines for this scenario.

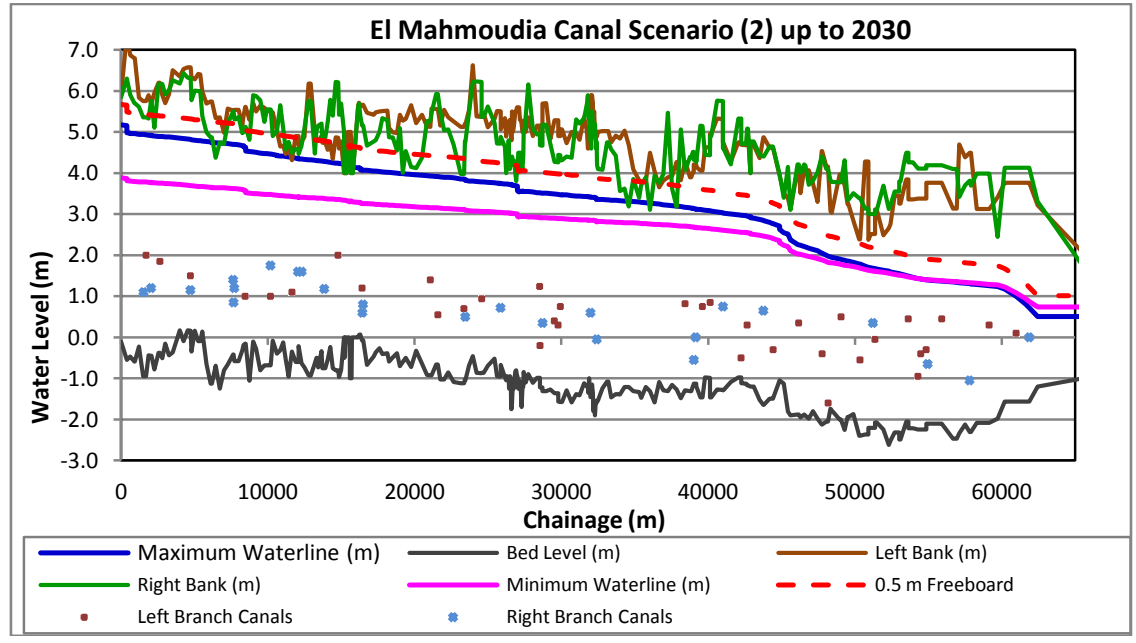

Figure 5: $\quad$ El Mahmoudia canal waterlines up to the year 2030.

This scenario resulted in higher water levels, along the whole length of the canal, than Scenario (1), leading to more areas of unachieved freeboard. The proposed interventions are also embankments raising at these locations. 


\section{Scenario (3) up to the year 2040}

Scenario (3) is the same as scenario (2) in using Decree 29:2010 rice areas for branch canals command areas, introducing drainage water re-use from the 7 existing re-use pump stations, increasing inflow from Edko in July, and decreasing that from El Khandaq El Sharqy in June through August. Moreover, inflow from El Atf pumping station was increased to reach 16.34 million $\mathrm{m}^{3} / \mathrm{sec}$, which is higher than the maximum capacity of the existing three pump stations. Accordingly, it is recommended to increase the capacity of El Atf pump station.

Engineering interventions were required to enhance the hydraulic conditions in the canal with a view to lowering water levels to address the freeboard issues. Between $\mathrm{Km} 0.000$ and $\mathrm{Km} 27.000$ there are a number of locations, within the canal, where the existing cross sections are contracting the flow. Consequently, rectangular cross sections of $56 \mathrm{~m}$ bed width at five locations $(\mathrm{km} 0.000$ till km $2.750, \mathrm{~km} 4.750$ till $\mathrm{km} 6.500, \mathrm{~km} 8.000$ till km 9.500, km 11.500 till km 13.500 ,

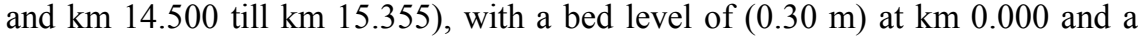
long slope of $3 \mathrm{~cm} / \mathrm{km}$, were introduced to the model. In addition to introducing rectangular cross sections of $50 \mathrm{~m}$ bed width at two locations $(\mathrm{km} 23.000$ till km 25.000 and $\mathrm{km} 26.000$ till $\mathrm{km} \mathrm{27.000)}$ with a bed level of $(-0.86 \mathrm{~m})$ at $\mathrm{km} 23.000$ and a long slope of $2.5 \mathrm{~cm} / \mathrm{km}$. The proposed rectangular sections should be accompanied by backfilling and embankment raising at their locations. Figure 6 presents the results of scenario (3).

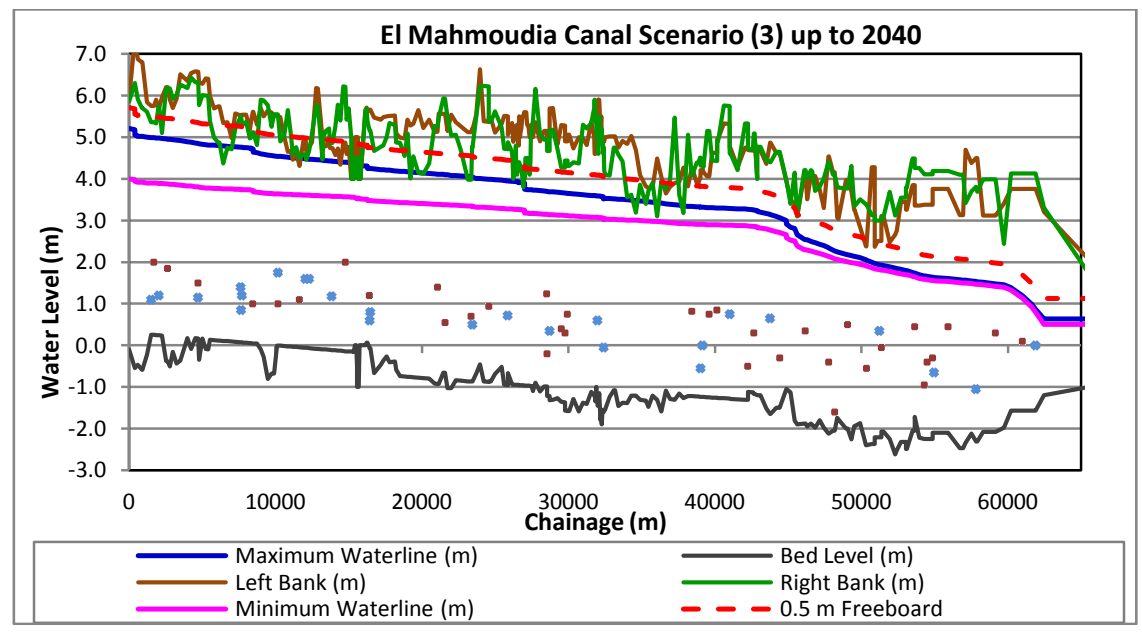

Figure 6: $\quad$ El Mahmoudia canal waterlines up to the year 2040.

\section{Scenario (4) up to the year 2050}

In this scenario, all the previously introduced assumptions and interventions were applied in addition to further modifications. Decree 29:2010 rice areas for branch canals command areas in addition to introducing drainage water re-use 
from the 7 re-use pump stations in June, July and August were applied. Inflow from El Atf pumping station was increased to reach approximately 17.50 million $\mathrm{m}^{3} / \mathrm{sec}$. i.e., the capacity of El Atf pumping station should be increased. Furthermore, inflow from Edko pump station was increased in July, while that from El Khandaq El Sharqy canal was reduced from May till August in order to balance the junction at El Khandaq El Sharqy confluence.

Rectangular cross sections at constraining locations were introduced as a second phase for El Mahmoudia canal engineering interventions in addition to raising embankments locally. Rectangular cross sections of $50 \mathrm{~m}$ bed width were introduced at two locations ( $\mathrm{km} 29.500$ till 32.000 and $\mathrm{km} 38.500$ till $\mathrm{km} 42.000)$ a bed level of $(-0.96 \mathrm{~m})$ was applied at $\mathrm{km} 27.000$ with a long slope of $2.5 \mathrm{~cm} / \mathrm{km}$. In addition to introducing rectangular cross sections of $45 \mathrm{~m}$ bed width at two locations $(\mathrm{km} 46.000$ till k 48.000 and $\mathrm{km} 49.500$ till $\mathrm{km} 53.500$ a horizontal bed of a level equals to $(-1.60 \mathrm{~m})$ was identified. Figure 7 presents the simulated maximum and minimum waterlines.

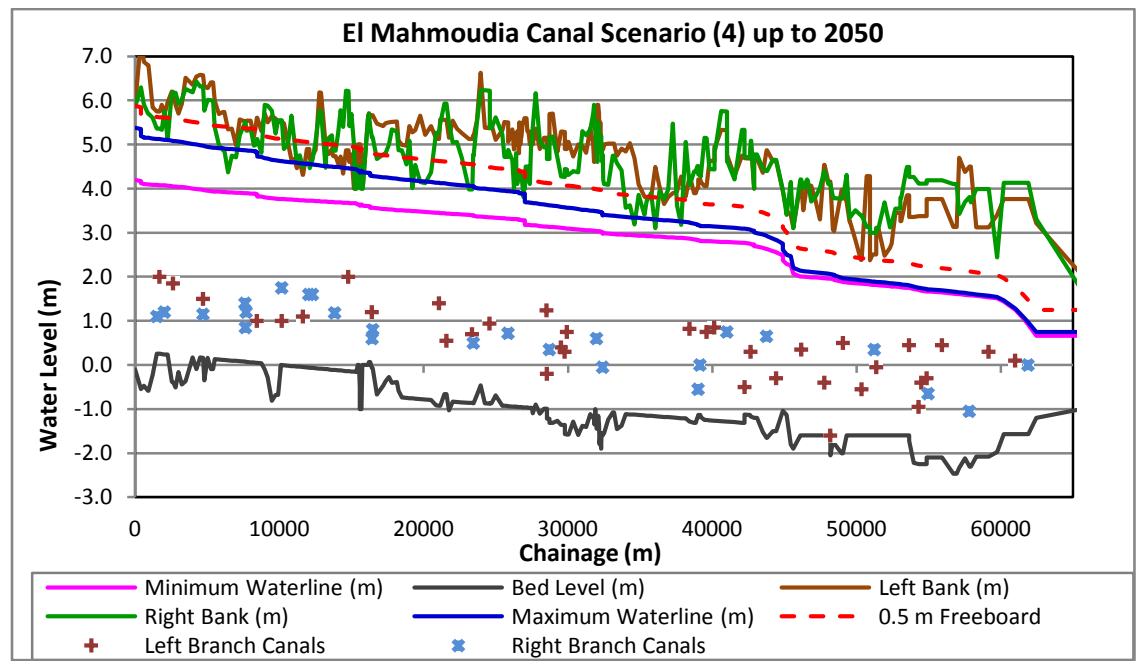

Figure 7: $\quad$ El Mahmoudia canal waterlines up to the year 2050.

\section{Summary and conclusion}

The main objective of this study is to identify the most effective physical interventions required to increase the carrying capacity of El Mahmoudia canal, selected as a case study, allowing the passage of future discharges up to the year 2050. According to the different introduced scenarios, the following conclusions can be identified:

- Inflows from El Khandaq El Sharqy to El Mahmoudia main canal are affected by the water levels in the main stream. As the water levels rise in El Mahmoudia canal, less water can enter the system at El Khandaq El Sharqy confluence and more must be added at El Atf pumping station. 
- The MWRI's Decree 29 sanctioned rice cultivation areas should be applied to the entire branch canals cropped areas within the command area. Moreover, small drainage re-use pumping stations should be allowed, to an extent, to supply branch canals' tails suffering from water shortage especially during peak demand time and water shortages.

- Rectangular cross sections with appropriate bed widths should be implemented at constraining locations along El Mahmoudia canal in order to enhance the hydraulic conditions in the canal and lower the water levels.

\section{References}

[1] Abou Rayan M., and Djebedjian B., (2004), "Egypt's Water Demand, Supply and Management Policies", International Water Demand Management Conference, Dead Sea, Jordon, 30 May-3 June

[2] Attia B. B., (2004), "Water as a Basic Human Right in Egypt", Global Issue Papers, No. 11, Supplement 1, The Understanding of Water in the Arab Countries of the Middle East - A Four Country Analysis, September.

[3] MWRI, (2005), "Integrated Water Resources Management Plan", the Ministry of Water Resources and Irrigation, Egypt, June.

[4] Allam M. N., and Allam G. I., (2007), "Water Resources in Egypt: Future Challenges and Opportunities", International Water Resources Association, Water International, Vol. 32, No. 2, PP. 205-218, June.

[5] Wagdy A., (2008), "Progress in Water Resources Management: Egypt", Proceedings of the 1st Technical Meeting of Muslim Water Researchers Cooperation, Malaysia, December.

[6] York E. T., Plucknett D., Ross J., and Youngberg H., (1994), "Report of a 1994 USAID-Sponsored Mission to Evaluate the National Agricultural Research Project in Egypt", The National Agricultural Research Project's Contributions to Significant Advances in Egyptian Agriculture, Tropical Research \& Development, Inc., Gainesville, Florida, USA, June.

[7] Hanna F., and Osman M. A., (1995), "Agricultural Land Resources and the Future of Land Reclamation and Development in Egypt", Egyptian Agriculture Profile, Centre International de Hautes Etudes Agronomiques Méditerranéennes, Montpellier, France.

[8] Abu Zeid M., (1995), "Major Policies and Programs for Irrigation Drainage and Water Resources Development in Egypt", Egyptian Agriculture Profile, Centre International de Hautes Etudes Agronomiques Méditerranéennes, Montpellier, France.

[9] Hvidt M., (1998), "Water, Technology and Development Upgrading Egypt's Irrigation System", Published by Tauris Academic Studies, London, Great Britain.

[10] Bader E., (2004), "Mathematical Programming Models for Optimizing Irrigation Water Management in Egypt", Ph. D. Thesis, Kiel University, Germany, November. 
[11] Abd El Azim N. F., (2006), "Development of the Irrigation Improvement Project in Bisintaway canal", M. Sc. Thesis, Alexandria University, Alexandria, Egypt, July.

[12] Gersfelt B., (2007), "Allocating Irrigation Water in Egypt", Case Study No. 8-4 of the Program: Food Policy for Developing Countries: The Role of Government in the Global Food System, Cornell University, Ithaca, New York.

[13] Kotb T., and Boissevain W., (2012), "Water Saving Due to Irrigation Improvement in the Nile Delta", The 5th International Conference BALWOIS on Water Climate and Environment, Ohrid, Republic of Macedonia, 28 May-2 June.

[14] Water Watch, (2009), "Remote Sensing Study for the Impact Monitoring of the Integrated Irrigation Improvement and Management Project", Draft Report, Water watch, Wageningen, September.

[15] CAPMAS, (2012), "Statistical Yearbook", the Central Agency for Public Mobilization and Statistics, Arab Republic of Egypt, September. 